\title{
Sexual and Marital Adjustment of World War II Spinal Cord Injured Veterans
}

\author{
V. Nikas, MD, P. Fleischman, MSW, P. Burton, MSW \\ Spinal Cord Injury Unit, Sepulveda VA Medical Center, 16111 Plummer Street, \\ Sepulveda, CA 91343, USA.
}

\section{Summary}

A survey of the marital and sexual adjustment of World War II spinal cord injured veterans was undertaken at the Spinal Cord Injury Outpatient Clinic at the VA Medical Center, Sepulveda, California. A questionnaire containing 42 questions was sent to 40 of these veterans who had survived more than 40 years after their injuries. Fifteen of the questionnaires were completed, with the results categorised in three areas: Demographic information, medical information, and marital and sexual information. A third of the subjects were quadriplegics, $66 \cdot 7 \%$ were paraplegics. Seventy eight per cent of the couples were of the same age group. Eighty per cent were married after their injury; $73 \cdot 4 \%$ were married to their original spouse. Two thirds of the SCI veterans fathered children. Of the fathers, $70 \%$ fathered children after their injury. Seventy five per cent of the veterans and $50 \%$ of their wives had education beyond high school. Forty per cent of the subjects used foley catheters, and 53.3\% reported symptoms of spasticity. Eighty per cent used alcohol socially and $20 \%$ used tobacco. $46.7 \%$ rated sex as unimportant in their lives, yet many reported that their sexual lives were unsatisfactory. Sex was not openly discussed with their spouses although 55\% reported excellent communication with their wives and $70 \%$ reported spending their leisure time with their wives. A significant response was the $86.6 \%$ of the subjects recommended marriage as a way of life for persons having a new spinal cord injury.

Key words: Spinal cord injured; World War II spinal cord injury veterans; Sexual adjustment; Marital adjustment.

Since World War II, with its resulting casualties, the number of spinal cord injured (SCI) patients in the USA has grown as treatment methods improved. One report (Gregory, 1974) states that by the end of World War II there were about 2000 such patients in Military and Veterans Administration Hospitals. Until World War II, few SCI patients survived long after their injury. In comparison, 400 Americans were removed from the battlefields of World War I with spinal cord injuries. Ninety per cent of these individuals were dead within 1 year after their injury. Gregory (1974) reports that many spinal cord injury patients from World War II 
were saved because of improved surgical techniques, treatment of shock, and the use of antibiotics to fight infection.

Major statistical surveys of the marital life of the World War II veterans do not exist in relation to physical, cultural, sexual, and psychosocial adjustment, and post-institutional care variables. In general, previous attempts to identify predictors of post-injury changes in marital status have been unsuccessful. Most papers have been published since 1960, by Commar (1962), Guttmann (1964), DeVoe (1974), Ghatit (1976), and DeVivo and Gale (1984). There is general agreement that stigmatisation exists for the spinal cord injured disabled, due to their complications, social, sexual, and personal.

'It is the aim of everyone concerned with the social resettlement of spinal cord sufferers to return as many of them as possible to their homes to live a near-normal life within the community.' (Guttmann, 1964). Naturally, one would expect that a disability of the magnitude of paraplegia and quadriplegia would create in its wake difficult problems in the domestic adjustments of these disabled people, particularly in regard to marital adjustment.

At the time of injury, rehabilitation efforts paid little or no attention to the sexuality of these spinal cord injury patients. However, World War II SCI veterans were seen as heroes of a just war and they had the support of our society. In addition, many nurses and other medical staff dedicated their professional lives to these deserving spinal cord injured veterans and provided comprehensive care, mutual concern, and respect. Intimate relationships also developed in many cases, resulting in marriages between SCI veterans and their nurses or other medical staff. In addition, some SCI veterans married women who were not medical care staff.

\section{Study methods}

The present paper investigates the adjustment of World War II spinal cord injury veterans in regard to their marital and sexual life. There are about 40 World War II spinal cord injured veterans who live in the San Fernando Valley area of Los Angeles, California. They are still alive and functioning more than 40 years after their injury. These 40 patients, with World War II military service dates, were selected from the population of outpatients enrolled in the SCI Clinic at the VA Medical Center, Sepulveda, California. They were selected for study due to having been affected by spinal cord injuries for many years.

A 47-item questionnaire was mailed to each of the 40 SCI veterans. To enhance candour, no subject was asked to divulge their identity and the questionnaires were returned anonymously. Of the 40 initial subjects, 15 completed and returned the questionnaires $(37 \cdot 5 \%)$.

In addition, 8 patients returned their questionnaires uncompleted with the comment that the questions were 'too personal'. This reluctance to directly address sexual and marital issues is also demonstrated in the responses to the questions on the survey form which indicated that many of the couples avoided this issue. The low response rate is likely due to this factor.

The questionnaires were designed to elicit information about the subjects' perception of their injury, marital status, sexual functioning, and other aspects of their lives described in this article. 


\section{Demographic information}

Table I Demographic information

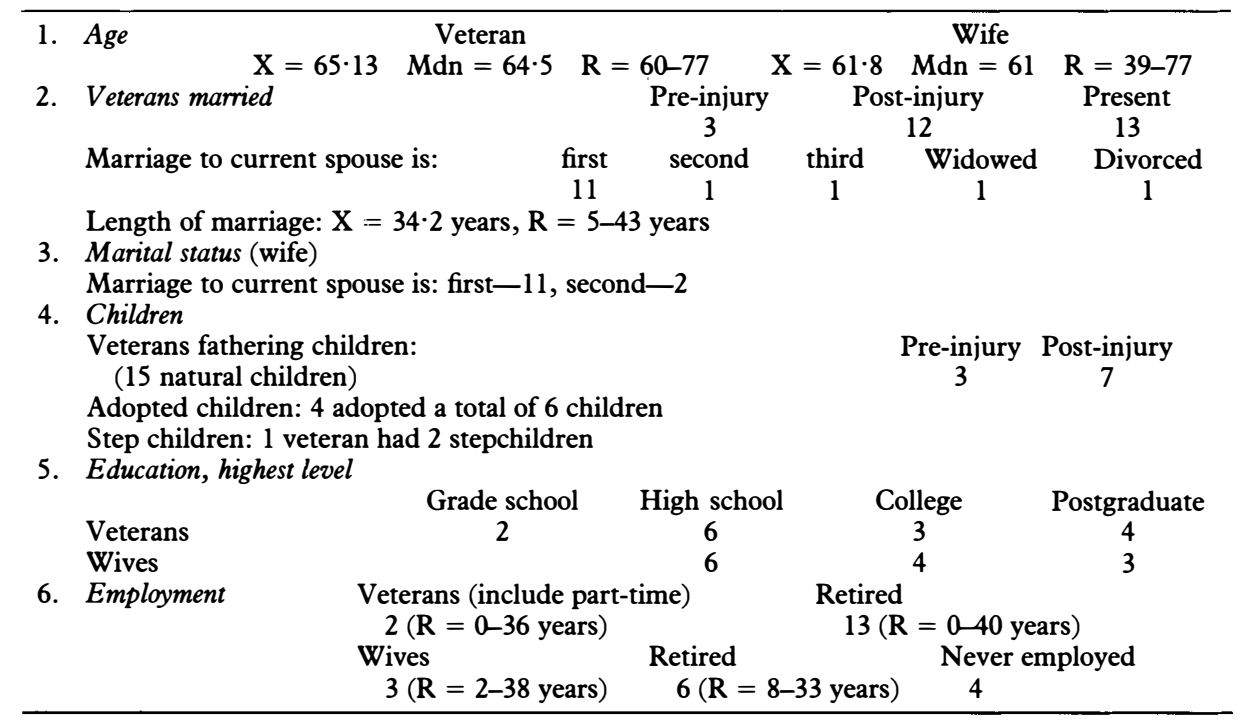

The demographic data (Table I) reveals that $78 \%$ of the couples were of the same age. Twenty per cent of the SCI veterans were married prior to their injury, $80 \%$ married after the injury. At the time of the study, a high percentage $(87 \%)$ were married, most to their original wife. A small percentage (13\%) were divorced or widowed.

Most of the wives had married their current spouse as their first marriage. The remainder $(27 \%)$ had married the veterans as their second marriage. Compared to the general population, with a divorce rate of over $50 \%$, we see a highly stable marriage pattern in this group.

Sixty seven per cent of the SCI veterans had fathered children, $30 \%$ before their injury and $70 \%$ after injury, producing a total of 15 natural children. In addition, some of these veterans adopted children or acquired stepchildren. The fertility is exceptionally high for this patient group, particularly when compared with the results published by Commar (1986), which showed only a $6.5 \%$ post-injury fertility rate.

About half (47\%) of these subjects had completed college, with several (27\%) continuing on with postgraduate education. The wives of this group are closely matched in education, with $54 \%$ completing college and $23 \%$ going on to postgraduate studies.

When compared with the general population of this age group, with a $29 \%$ high school completion rate, we see a generally well-educated group.

Most $(87 \%)$ of the SCI veterans were retired at the time of the study. The rest were employed part-time. Although all of these veterans were rated $100 \%$ disabled by the Veterans Administration, and received substantial compensation, they had all been productively employed during their lives. Consistent with this age group, 
a lower percentage of wives than husbands had been employed (69\%). However, it was a higher percentage than the general population for this age group.

\section{Medical information}

Table II Medical information

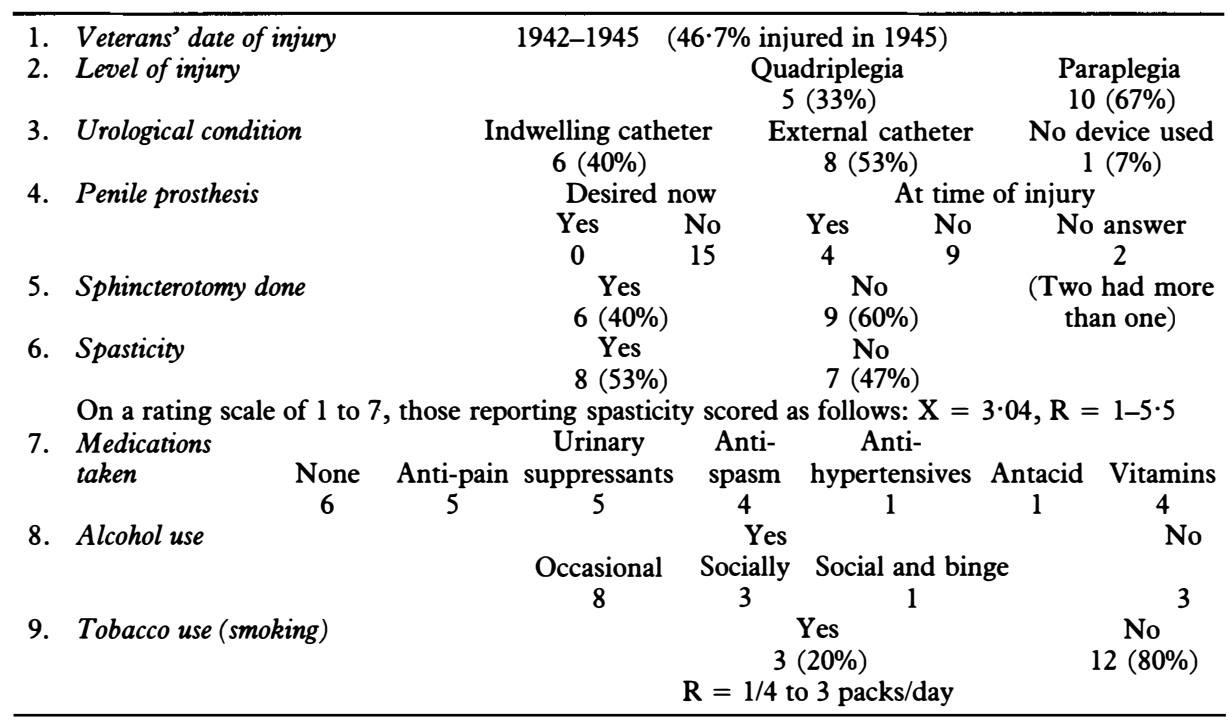

None of the wives were SCI patients (Table II). All of the respondents were asked to list the specific site of their injury. However the self-reports were not reliable as the patients responding indicated their level of injury as 'quadriplegia' or 'paraplegia'. Thus, the data returned on the questionnaires does not allow an objective classification of the injury sites. No data was given about the length of time indwelling catheters had been used or about the incidence of urinary tract infections or renal stones. Part of the reason may be that the question about infections used the term 'UTI' instead of spelling out completely what was meant. This was based on the assumption that the patients would know this term, which may not have been an accurate assessment.

No penile prosthetic devices were reported used, and there was no reported desire to obtain such a device. Forty per cent reported they would have wanted such a device at the time of their injury, but $60 \%$ indicated they would have never had any interest in such a device.

The patients who had received TUR external sphincterotomy had the most complaints about their sexual lives.

It was also noted that the more educated group comprised the non-smokers, but this group also used alcohol more frequently. 


\section{Social and marital information}

The majority of the SCI veterans do not engage in sexual intercourse currently (Table III). Comparing the immediate post-injury sexual activity with the current sexual activity, we see a decline, probably due to the normal aging process.

There was no universal or dominant sexual position used by these couples. Most of the SCI veterans $(60 \%)$ stated that their sexual lives had been different from the general population.

In rating the importance of sex in a marital relationship, there was a polarised (dichotomous) response, with $47 \%$ rating sex as unimportant, and $27 \%$ rating it as very important.

These patients also believe that their sexuality is not the same as 'normal' people who have no spinal cord injury. The responses to question 6 indicate that they feel 'different', without any hard data on which to base their self-perceptions.

Comparing the responses to the questions 7,8 and 9 , we see that the majority feel that sexuality is not important in marriage, but they see their sexuality as unsatisfactory and do not discuss it openly with their spouses. The clinical experience in providing sex therapy by one of the authors indicates that difficulty in discussing sexual issues is common for this age group.

With regard to the expenditure of leisure time with wives, $70 \%$ answered positively to joint time expenditures. Since the majority of these veterans are retired, it is significant to note that these couples spend a lot of their time together.

One question not displayed in a table due to varied and inconclusive responses concerned the expression of feelings other than sexual. The most dominant response $(54 \%)$ indicated that four avenues of expression (tenderness, mutual concern, love, affection) were used primarily by this group. It was unfortunate the question was worded in such a way as to confuse the respondents.

When asked to list the things that they argue about, responses were elicited from 6 of the respondents (54\%). The responses included arguing about children and drugs, money, housework, 'minor things', 'about ourselves', and about 'cultural, political, religious, etc.'

Fifty four per cent reported an excellent level of communication with their wives, although there was some doubt when compared with the responses to question 7 related to discussion of sexual issues where $47 \%$ did not discuss the subject at all. Thus, there was apparently an attempt to focus discussion on 'safe' issues.

The majority of patients indicated that they believed that both SCI patients and their spouses should receive sex education following injury.

Eighty seven per cent recommended marriage as a way of life for other spinal cord injured patients, while only $13 \%$ did not recommend marriage. This $87 \%$ recommending marriage is the same as the number in the sample who were married, suggesting an overall level of satisfaction with the marital situation.

\section{Summary and conclusions}

The information gained in this study indicates that long term marital and sexual relationships are a definite option for those incurring a spinal cord injury. Most previous studies have focused on the high divorce rate for this group. There has 
Table III Sexual and marital information

1. Sexual experience

(a) Intercourse:

(b) Oral sex

(c) Manual stimulation:

(d) Masturbation:

(e) Erection:

\section{Pre-injury}

Yes $=10(67 \%) \quad R=0-3$ wk

No $=5(33 \%)$

Yes $=2(13 \%)($ rarely $)$

No $=9(60 \%)$

No answer-4 (27\%)

Yes $=0$

No $=12(80 \%)$

No answer-3

Yes $=8(53 \%)$

$\mathrm{R}=0-5 \times$ week

No $=6(40 \%)$

No answer-1

Yes $=15(100 \%)$

2. Current sexual activity
(a) Intercourse attempted

Yes $5(33 \%)$

No
(b) Erection Reflexogenic

(c) Ejaculation

(d) Orgasm

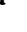
Yes $=3(20 \%)$ Psychogenic 1 Both Yes $=2(13 \%) \quad$ No $=10(67 \%) \quad$ No answer-3 Yes $=1(7 \%) \quad$ No $=11(73 \%) \quad$ No answer-3

3. Sexual positions used $\begin{array}{cc}\text { Male } & \text { Female } \\ \text { above } & \text { above } \\ 2 & 2\end{array}$

4. Time of sexual activity Morning Evening 34
Alternate Side/side Rear 120
Afternoon and Evening 1

Other
Multiple
No answer

01

2

Morning and Evening

No answer

5. Changes in frequency of sexual activity related to age

$\begin{array}{ccccccc}\text { Increase } & \text { Decrease } & \text { Same } & \text { Stopped } & \begin{array}{c}\text { Same and } \\ \text { stopped }\end{array} & \begin{array}{c}\text { Decreased } \\ \text { and stopped }\end{array} & \begin{array}{c}\text { No } \\ \text { answer }\end{array} \\ 0 & 4 & 2 & 4 & 1 & 3 & 1\end{array}$

6. Self-perception/comparison of sexual activity with non-SCI $\begin{array}{cc}\text { Same as } & \text { Not the same } \\ 1 & 9\end{array}$ 9

Don't know No answer

7. Importance of sexuality in marriage Minimal

Very important
(1)
(2)
(3)
(4)
(5)

$\begin{array}{ccc}7 & 0 & 1 \\ \text { Current } & \text { sexual satisf action }\end{array}$ Very unsatisfactory
(1) 12 (2)
(3)

9. Discussion of sex with wife Not at all
(1)
(2)
$7 \quad 2$
$(3)$
0
(4)
0

(4)

5

(5)

Very satisfactory
(6)
(7) $\mathrm{X}=3.36$
$4 \quad \mathrm{R}=1-7$
(6)
0
(7) $\mathrm{X}=3 \cdot 21$

(5)

1

$$
\begin{aligned}
& \text { Post-injury } \\
& \text { Yes }=7(47 \%) \\
& \mathrm{R}=0-0 \cdot 3 \text { week } \\
& \text { No }=5(33 \%) \\
& \text { No answer } 3(20 \%) \\
& \text { Yes }=2(13 \%) \\
& \mathrm{R}=0-5 \times \text { week } \\
& \text { No }=7(47 \%) \\
& \text { No answer-4 } \\
& \text { Yes }=4(27 \%) \\
& \mathrm{R}=0-7 \times \text { week } \\
& \text { No }=7(47 \%) \\
& \text { No answer-4 } \\
& \text { Yes }=2(13 \%) \\
& \text { No }=12(80 \%) \\
& \text { No answer-4 } \\
& \text { Yes }=8(53 \%) \\
& \text { Reflex }=4 \\
& \text { Psychogenic }=1 \\
& \text { Both }=3 \\
& \text { No }=5(33 \%)
\end{aligned}
$$


TABLE III-continued

10. Leisure time spent Separately

(1) (2)

2 $\begin{array}{cc}0 & \\ \text { No wife }-2 & 1\end{array}$

11. Arguing with wife Always

(1) (2)

No wife-2
(3)

0
(4)

1

(5)

3

(6)

2

Together

(7) $\quad X=4 \cdot 8$

12. Communication with wife Poor

$\begin{array}{cccc}(1) & (2) & (3) & (4) \\ 0 & 0 & 2 & 4\end{array}$

(4)

(5)

(6)

Never

2

5

(7)

(7) $\mathrm{X}=5 \cdot 61$

$R=4-7$

No wife- 1 , Previous spouse -1

13. Sex education wanted

\begin{tabular}{ccc}
\multicolumn{3}{c}{ Patient alone } \\
Yes & No & No answer \\
2 & 3 & 10 \\
$13 \%$ & $20 \%$ & $67 \%$
\end{tabular}

14. Would recommend marriage to new SCI patient

(5)

1

(6)

Excellent

$$
\begin{array}{ll}
(7) & X=5 \cdot 57 \\
7 & R=3-7
\end{array}
$$




\section{Spontaneous comments}

Some of the respondents gave written comments in response to an invitation to do so on an open ended question. Some of the comments are the following. They are provided for general interest, and because the authors believe they are probably representative of how many SCI patients feel.

From a veteran's wife: 'It is possible for social, religious, or economic reasons to maintain the outward appearance of a stable marriage. However, within the marriage (behind closed doors) there is much repressed anguish. I think there should be a strong and very sensitive programme of sex education for SCI and their present or potential wives, both separately and together. They should know what the odds are, especially those who have not yet committed themselves. I strongly recommend at least a year of "trial marriage" outside the hospital before making a lifetime statement.'

From a SCI veteran: 'If you get married, be sure you like the woman not merely "be in love". Mutual respect and loving one another will smooth out a lot of bumps and don't be too quick in a flash of anger to split up.'

From another veteran: 'As you know, there is not two SCI alike, so my adviceattend a guidance class. Eliminate your mental block and go with what you have!'

Suggestion for the newly injured SCI patient: 'Be sure you understand each other's wants and needs and be willing to go more than half way, but don't marry to get someone to take care of you. Above all, don't feel sorry for yourself. Keep your body and mind healthy by exercise and hobbies, or work if you can.'

\section{References}

ABrams KS 1981 The impact of marriages of adult onset paraplegia. Paraplegia 19:253-259.

Bors E 1965 Sexual function in patients with spinal cord injuries Harris (ed.) Spinal Injuries, Morrison \& Gibb, Ltd.

COMARR AE 1962 Marriage and divorce among patients with spinal cord injury. Fournal of the Indian Medical Profession 9:4353-4359.

COMARR AE 1970 Sexual function among patients with spinal cord injury. Urology International 25:134-168.

COMARR AE 1985 Sexuality and fertility among spinal cord or quada equina injury. Fournal of the American Paraplegia Society 8(4):67-74.

DE VIvo MJ, FINE PR 1985 Spinal cord injury, its short term impact on marital status. Archives of Physical Medicine and Rehabilitation 66:501-504.

DEYOE FS 1972 Marriage and family patterns with long term spinal cord injury. Paraplegia 10:219224.

El Ghatit AZ, Hanson RW 1976 Marriage and divorce after spinal cord injury. Archives of Physical Medicine and Rehabilitation 57:470-472.

GREGORY MF 1980 Sexual adjustment, a guide for spinal cord injury. Accent on Living Magazine.

GutTMANN L 1964 The married life of paraplegics and tetraplegics. Paraplegia 2:182-188.

Young EW 1984 Patient's plea: tell us about our sexuality. Fournal of Sex Education E Therapy 10(2):53-56. 